2018

\title{
Building a Culture of Assessment in Law Schools
}

Larry Cunningham

Follow this and additional works at: https://scholarlycommons.law.case.edu/caselrev

Part of the Law Commons

\section{Recommended Citation}

Larry Cunningham, Building a Culture of Assessment in Law Schools, 69 Case W. Rsrv. L. Rev. 395 (2018) Available at: https://scholarlycommons.law.case.edu/caselrev/vol69/iss2/8

This Article is brought to you for free and open access by the Student Journals at Case Western Reserve University School of Law Scholarly Commons. It has been accepted for inclusion in Case Western Reserve Law Review by an authorized administrator of Case Western Reserve University School of Law Scholarly Commons. 


\title{
Building A Culture of Assessment IN LAW SCHOOLS
}

\author{
Larry Cunningham
}

\begin{abstract}
A new era of legal education is upon us: law schools are now required to assess learning outcomes across their degrees and programs, not just in individual courses. Programmatic assessment is new to legal education, but it has existed in higher education for decades. To be successful, assessment requires cooperation and buy-in from faculty. Yet establishing a culture of assessment in other disciplines has not been easy, and there is no reason to believe that it will be any different in legal education. A survey of provosts identified faculty buy-in as the single biggest challenge towards implementing assessment efforts. This Article surveys the literature on culture of assessment, including conceptual papers and quantitative and qualitative studies. It then draws ten themes from the literature about how to build a culture of assessment: (1) the purpose of assessment, which is a form of scholarship, is improving student learning and is not just for satisfying accreditors; (2) assessment must be faculty-driven; (3) messaging and communication around assessment is critical, from the reasons for assessment through celebrating successes; (4) faculty should be provided professional development, including in their own graduate studies; (5) resources are important; (6) successes should be rewarded and recognized; (7) priority should be given to utilizing faculty's existing assessment devices rather than employing externally developed tests; (8) the unique needs of contingent faculty and other populations should be considered; (9) to accomplish change, stakeholders should draw on theories of leadership, business, motivation, and the social process of innovation; and (10) student affairs should be integrated with faculty and academic assessment activities. These themes, if implemented by law schools, will help programmatic assessment to become an effective addition to legal education and not just something viewed as a regulatory burden.
\end{abstract}

Keywords: culture of assessment, faculty, learning outcomes, innovation, change management.

$\dagger \quad$ Associate Dean for Assessment and Institutional Effectiveness, Professor of Legal Writing, and Director of the Center for Trial and Appellate Advocacy, St. John's University School of Law. Copyright (9) 2018 Larry Cunningham. Contact information: Larry.Cunningham@stjohns.edu. The author would like to thank Matthew Fuller, Ph.D., Sam Houston State University, for his comments on an earlier draft of this Article. 


\section{Contents}

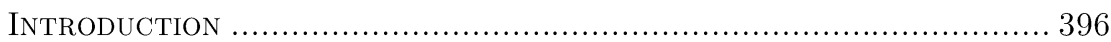

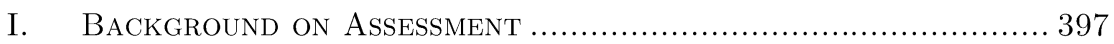

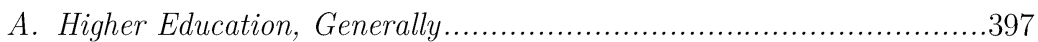

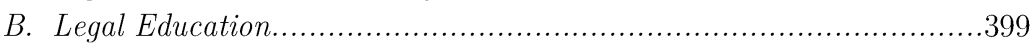

II. The Need for a Culture Shift Around Assessment in Higher Education .................................................... 405

III. Conceptual Views of Building a Culture of Assessment...... 408

IV. Quantitative and Qualitative Studies on Assessment

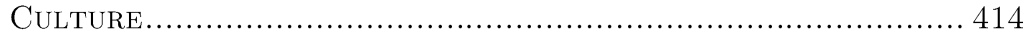

V. ImPLiCATIONS FOR LEGAL EdUCATION .................................... 421

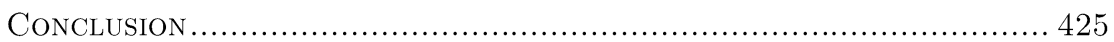

\section{INTRODUCTION}

Programmatic assessment is the process by which a college or program identifies, through concrete evidence, whether its students are meeting the learning outcomes that the college or program has identified for itself and using the results to improve student learning. ${ }^{1}$ The purpose of assessment is to have a data-driven process in place to improve student learning. ${ }^{2}$ This approach is new to law schools - the American Bar Association first began implementing new, outcomedriven accreditation standards in 2016-2017-but has been in effect in the rest of higher education for decades. ${ }^{3}$ Indeed, legal education is the last major discipline to adopt assessment. Medicine, dentistry, architecture, and others have all preceded our field in measuring and documenting student outcomes as to learning. ${ }^{4}$ The six regional accreditors of colleges and universities, driven by the Department of Education, have also required an outcomes-oriented approach to accreditation. ${ }^{5}$ As the proverbial new kid on the assessment block, legal

1. See Trudy W. Banta \& Catherine A. Palomba, Assessment Essentials: Planning, Implementing, and Improving Assessment in Higher Education 1-3 (2d ed. 2015) (describing the evolution of the term "assessment" as used and understood in the context of evaluating higher education institutions).

2. Id. at 9-11.

3. See id. at 3-7 (highlighting the history of accreditation standards for higher learning institutions).

4. See infra notes 31-37 and accompanying text (describing ABA Outcome Measures Committee findings about assessment in other professional disciplines).

5. Banta \& PAlOMBa, supra note 1 , at 5 . 
education has the opportunity to learn from those disciplines that have gone before us.

One of the assessment challenges that our colleagues in higher education have noted is getting faculty buy-in for assessment. ${ }^{6}$ While administrative support for assessment is important, the faculty play the most important role in assessment, since they are closest to the students, are administering assessments anyway, and are able to make changes to the curriculum or teaching methods as a result of assessment findings. How to develop a so-called "culture of assessment"-where faculty, staff, and students "act on the common understanding that assessment can improve the campus" - is the subject of this Article.

There is extensive higher education literature upon which legal educators can draw to help them build a culture of assessment at their schools. ${ }^{8}$ This Article surveys this literature and draws from it ten themes for successfully implementing programmatic assessment in a unit. ${ }^{9}$ These themes will be important for law schools to utilize as they begin to implement the new ABA standards.

This Article will proceed as follows. Part I will provide an overview of assessment, both its general adoption in higher education and recent efforts to bring it to legal education. Part II will address the importance behind faculty engagement and shifting the focus from compliance and report-writing to the true value of assessment: improving student learning. Part III will address the arguments from the foundational literature on assessment on how to build a culture of assessment. Part IV will review the quantitative and qualitative studies that have explored particular initiatives at faculty and other end users' engagement with assessment. Finally, in Part V, ten themes will be distilled from the literature about how assessment can be effectively deployed in law schools.

\section{BaCkground on Assessment}

\section{A. Higher Education, Generally}

"Assessment" has varying meanings in higher education. It can refer to the formative feedback that a professor provides student in an individual course, and it can also mean the summative grades that are assigned during or after a semester measuring a student's progress. It

6. See infra Part I.

7. Banta \& Palomba, supra note 1, at 276; see also infra Part I.

8. See infra Parts II, III, and IV.

9. See infra Part V. 
may also refer to institution-level metrics around strategic planning goals. ${ }^{10}$

Since at least the 1970s, a different format of assessment has become prominent on college campuses: programmatic assessment of student learning outcomes. ${ }^{11}$ In this context, "assessment" means the process by which stakeholders measure the extent to which students are meeting learning outcomes that have been defined for an institution, school, or program, and using the results to close the loop and improve student learning further. ${ }^{12}$ To that end, it involves compiling data on student learning, often across multiple courses. ${ }^{13}$

This form of assessment is markedly different from what takes place at the course level. No longer is it sufficient for a professor, in the solitude of his or her office, to just assign grades to his or her students. Institutions of higher education are now asked to document learning across courses: by program, school, and even the institution itself. ${ }^{14}$ It differs from grading because the assignment of a grade is a summary measure of performance in a particular class and may measure numerous, overlapping outcomes. Grading may also be relative, showing how a student did compared to others in the class, but without telling us anything about how much the student has learned. ${ }^{15}$

This form of assessment grew out of accreditation and accountability efforts. It has roots in national reports highlighting the varied preparation of college graduates ${ }^{16}$ and in government efforts calling for greater accountability in higher education. ${ }^{17}$ Following suit,

10. BANTA \& PAlOMBA, supra note 1, at 1-3.

11. Id. at $3-7$.

12. Id. at $1-2$.

13. See Don Haviland et al., Now I'm Ready: The Impact of a Professional Development Initiative on Faculty Concerns with Program Assessment, 35 Innovative Higher Educ. 261, 262-63 (2010) (discussing the need for faculty members to come together and share their data about individual students to be able to assess the course as a whole).

14. Banta \& Palomba, supra note 1 , at 9-11.

15. Tara Eisenhauer Ebersole, Postsecondary Assessment: Faculty Attitudes and Levels of Engagement, 21(2) Assessment Update, Mar.-Apr. 2009, at 1 .

16. Xueli Wang \& Sarah Hurley, Assessment as a Scholarly Activity? Faculty Perceptions of and Willingness to Engage in Student Learning Assessment, 61 J. Gen. Educ. 1, 1 (2012).

17. Christopher A. McCullough \& Elizabeth Jones, Creating a Culture of Faculty Participation in Assessment: Factors that Promote and Impede Satisfaction, 4 J. Assessment \& Institutional Effectiveness 85, 86 (2014); Maureen Snow Andrade, Managing Change-Engaging Faculty in Assessment Opportunities, 36 Innovative Higher Educ. 217, 217 (2011). 
regional and specialty accreditors have demanded, for some years now, that universities and colleges have processes in place to measure the extent to which their students are learning. ${ }^{18}$

Unsurprisingly, given these external pressures, there is evidence that universities and colleges are engaging in assessment. ${ }^{19}$ A Spring 2009 survey of provosts found that most institutions have engaged in some form of assessment, but the most common use of assessment data was for accreditation purposes. When asked what they need to do a more effective job at assessing learning outcomes, provosts identified faculty engagement (66\%) and developing greater expertise in assessment $(61 \%)$ as most needed. ${ }^{20}$ At doctoral research universities, $80 \%$ of provosts reported greater faculty engagement as the most pressing challenge. ${ }^{21}$

Many have argued that, to be effective in the long-term, assessment must move from a culture of compliance to one where faculty, administrators, and governing boards are genuinely interested and engaged with assessment for the purpose of improving student learning. ${ }^{22}$ Moving an institution's culture from compliance to genuine, scholarly interest in assessment has been the subject of many studies. Researches have sought to identify how a university or college can adopt a "culture of assessment," otherwise known as a "sustainable culture of inquiry," 23 or a "culture of evidence and betterment." 24 The particular focus of this Article is how to adopt such a culture of assessment within law faculty, who, as a group, are among the most skeptical about programmatic assessment yet whose buy-in will be essential to successful assessment efforts. ${ }^{25}$

\section{B. Legal Education}

Like other units in higher education, law schools are experimenting with assessment as a result of pressure from the accreditation process.

18. Andrade, supra note 17 , at 217.

19. Michael R. Lane et al., Improving Assessment: Creating a Culture of Assessment with a Change Management Approach, 4 J. CASE Studies ACCREditation \& Assessment 1, 2 (Dec. 2014).

20. George Kuh \& Stanley Ikenberry, More Than You Think, Less Than We Need: Learning Outcomes Assessment in American Higher Education 24 (2009).

21. Id.

22. See Haviland et al., supra note 13, at 263.

23. Peggy L. Maki, Assessing for Learning: Building a Sustainable Commitment Across the Institution 3 (2010).

24. Linda Suskie, Assessing Student Learning: A Common Sense Guide 118 (3d ed. 2018).

25. Lane et al., supra note 19 , at 2-3. 
Prior to 2014, the ABA Standards for the Approval of Law Schools were primarily focused on "inputs," such as faculty headcounts, library books, and financial resources. ${ }^{26}$

In 2007, the then-chair of the ABA's Section of Legal Education and Admissions to the Bar, Chief Justice Ruth McGregor (Arizona Supreme Court), appointed a Special Committee on Outcome Measures. ${ }^{27}$ This committee was charged with determining how the ABA could use outcome measures, other than bar passage and career placement, in accreditation. ${ }^{28}$ That committee very quickly began its work and issued a report in 2008 that recommended the adoption of outcome-based assessment standards. ${ }^{29}$ The sweeping report concluded: "a shift towards outcome measures is consistent with the latest and best thinking of U.S. legal educators and legal educators in other countries and is also consistent with insights gleaned from legal practice and from accreditors in other fields of professional education." 30

A key aspect of the report was its study of ten professions for comparison purposes: allopathic and osteopathic medicine, dentistry, veterinary medicine, pharmacy, psychology, teaching, engineering, accounting, and architecture. ${ }^{31}$ Notably, all ten professions had moved from input-based systems to outcome measures. ${ }^{32}$ Dentistry had done so as early as $1988 .^{33}$ Legal education was alone in not utilizing outcomes assessment for accreditation purposes.

The committee found two consistencies across the ten professions. First, accreditors in those fields measured a school's performance against the school's own stated missions. That is, the accreditors did

26. Janet W. Fisher, Putting Students at the Center of Legal Education: How an Emphasis on Outcome Measure in the ABA Standards for Approval of Law Schools Might Transform the Educational Experience of Law Students, 35 S. Ill. U. L. J. 225, 228 (2011); ABA Outcome Measures Committee, Report of the Outcome Measures Committee (2008), https://www.americanbar.org/groups/legal_education/committees/ standards_review/comp_review_archive/special_committee_reports.html [https://perma.cc/7Y3P-4Z59] [hereinafter OutCOMES REPORT].

27. Memorandum from the Chief Justice of the Arizona Supreme Court to Committee members of the American Bar Association Section of Legal Education and Admissions to the Bar (Oct. 8, 2007) (available at https://www.americanbar.org/content/dam/aba/administrative/legal education_and_admissions_to_the_bar/standards_review/2007_special committee_appointment.authcheckdam.pdf [https://perma.cc/PB3J-W73J]).

28. Id.

29. Outcomes Report, supra note 26 , at 1.

30. Id.

31. Id. at 20 .

32. Id.

33. Id. 
not establish universal criteria for all schools to follow; instead, individual schools were free to adopt the measures that they thought were best for their missions. ${ }^{34}$ The second finding was that accreditation standards were "performance-based" and sought "evidence of student learning." "35 The focus is, therefore, on what is learned, not what is taught or what resources are provided. ${ }^{36}$ Moreover, post-graduate licensing exams were only partially helpful in this regard. Only one of the ten accreditors set a minimum floor for passage of the licensure exam. $^{37}$

Most law schools are also accredited-either independently or through their universities - by one of six regional accreditors recognized by the Department of Education. ${ }^{38}$ The regional accreditors have also moved from inputs to outputs and require universities to "collect and evaluate evidence to demonstrate that the institution is satisfying its mission as defined by the institution." 39 The report noted that, until recently, schools had largely been able to ignore assessment pressures from regional accreditors:

As the regional accreditors have begun holding accredited schools accountable for demonstrating educational effectiveness at all levels, law schools are no longer able to fly beneath the regional radar screen. As universities come up for reaccreditation reviews under these revised standards, the law schools are being required to actively participate in the process. As many law deans have already learned, this requires a rather dramatic paradigm shift in the way the law school evaluates its success. ${ }^{40}$

Ultimately, the Outcome Measures Committee recommended changes to the ABA standards with four guiding principles in mind:

1. Aside from the traditional curricular requirements found in the current Standards, the outcome Standards should provide law schools substantial flexibility in identifying outcomes that are consistent with their missions.

2. The outcomes Standards should not impose unnecessary costs on law schools. In particular, burdensome assessment
34. Id. at 21 .
35. Id.
36. Id.
37. Id. at 46 .
38. Id. at $46-47$.
39. Id. at 47 .
40. Id. 
regimes of individual student achievement for each learning outcome should not be required.

3. Law schools should have flexibility in determining what assessment methods to use across the curriculum.

4. A phase-in period for development of learning outcomes and assessment methods by law schools should be provided. ${ }^{41}$

Understandably, there was resistance to the proposal. ${ }^{42}$ The new standards were proposed and then adopted during a turbulent time in legal education, with decreased employment outcomes for students, ${ }^{43}$ increased media scrutiny, ${ }^{44}$ and a historic drop in applications to law schools. ${ }^{45}$ Deans expressed concern about the costs of assessment and whether lawyering skills could actually be measured. ${ }^{46}$

The ABA Standards Review Committee and, later, the Council on Legal Education and Admissions to the Bar took up the report and adopted a sweeping set of changes to the accreditation standards that implemented the Outcome Measures Committee's report. ${ }^{47}$ They were adopted in 2014 but had a multi-year phase-in process for the new standards related to assessment. There were four key standards that related to outcomes and assessment:

41. ABA Section of Legal Educ. And Admissions to the Bar, EXPlANATION OF CHANGes (2014), https://www.americanbar.org/content/

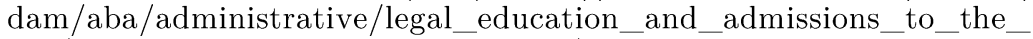
bar/council_reports_and_resolutions/201408_explanation_changes. authcheckdam.pdf [https://perma.cc/QEZ3-ZWTB] [hereinafter ABA, EXPLANATION OF CHANGES].

42. Katherine Mangan, Law Schools Resist Proposal to Assess Them Based on What Students Learn, Chron. Higher Educ. (Jan. 10, 2010), https://chronicle.com/article/Law-Schools-Resist-Proposal-to/63494/ [https://perma.cc/8Q5U-ZGLT].

43. Jordan Weissmann, The Jobs Crisis at Our Best Law Schools Is Much, Much Worse Than You Think, Atlantic (Apr. 9, 2013), https:// www.theatlantic.com/business/archive/2013/04/the-jobs-crisis-at-our-bestlaw-schools-is-much-much-worse-than-you-think/274795/ [https://perma.cc/ XSU6-E3K9].

44. Editorial, Legal Education Reform, N.Y. Times, Nov. 25, 2011, at A18.

45. Terry Carter, Reduction in Law School Applications Result in Favorable Upsides for Some, A.B.A J. (Aug. 10, 2017, 10:08 AM), https://www. abajournal.com/news/article/reduction_in_law_school_admissions_favor applicants_in_several_ways [https://perma.cc/4ZL3-AHTN].

46. Mangan, supra note 42.

47. ABA, Explanation of Changes, supra note 41. 
- $\quad$ Standard 301(b) was added. It requires law schools to establish and publish learning outcomes to achieve the objectives of its program of legal education. ${ }^{48}$

- Standard 302 was revised and now outlines the minimum learning outcomes a school must establish, including knowledge and understanding of the law, both procedural and substantive; legal analysis and reasoning; legal research; problem-solving; writing and oral communication in the legal context; exercise of professional and ethical responsibilities; and a catch-all of "other professional skills" that are needed to be a competent and ethical member of the legal profession. ${ }^{49}$ Interpretation 3022 makes clear that these outcomes are a floor, not a ceiling, and that a school may also identify any other learning outcomes pertinent to its mission. ${ }^{50}$

- Standard 314 was added. It requires law schools to use assessment methods that both measure (summative assessment) and improve (formative assessment) student learning. ${ }^{51}$ An interpretation notes that multiple assessments are not required for any particular course, and the methods used are likely to vary school-by-school. ${ }^{52}$

- Standard 315, also new, requires an "ongoing evaluation of the law school's program of legal education, learning outcomes, and assessment methods." ${ }^{53}$ This standard has several important points. First, the responsibility for assessment is with both the dean and "the faculty," implying that it is not the province of a small group of faculty or an administrative office. ${ }^{54}$ Second, assessment must be "ongoing" and the results must be used for two purposes: (1) to determine the degree to which students

48. ABA Section of Legal Education and Admissions to the Bar, aba Standards and Rules of Procedure for Approval of LaW SchoOLS 2018-2019 Ch. 3, Standard 301(b) (2018), https://www. americanbar.org/content/dam/aba/publications/misc/legal_education/ Standards/2018-2019ABAStandardsforApprovalofLawSchools/2018-2019aba-standards-rules-approval-law-schools-final.authcheckdam.pdf [https:// perma.cc/Y2XF-6GA3].

49. Id. Standard 302.

50. Id. Standard 302.

51. Id. Standard 314.

52. Id.

53. Id.

54. Id. 
are attaining a particular competency, and (2) to make "appropriate changes" to the curriculum (so-called closing of the loop). ${ }^{55}$ An interpretation provides examples of assessment methods and again notes that school-by-school differences are to be expected. ${ }^{56}$

Shortly after the new standards were announced, the Managing Director's Office released a non-binding guidance memorandum to deans about assessment of student learning outcomes. ${ }^{57}$ Most relevant to the discussion of building a culture of assessment, the Managing Director noted several points about the role of faculty in assessment. ${ }^{58}$ First, different types of faculty (doctrinal, clinical, legal writing, etc.) play important roles in assessment. ${ }^{59}$ Second, the process must be faculty-driven: "Faculty should have the central role in identifying, assessing and improving learning outcomes." 60 Third, the process is collaborative and cannot be relegated to a single individual. ${ }^{61}$ Finally, there was a phase-in process for the new standards, which were adopted in 2014 but did not take effect until 2016-2017. ${ }^{62}$ In 2016-2017, schools being evaluated by site teams had to show "progress" in establishing learning outcomes and an assessment plan. ${ }^{63}$ All schools were required to have learning outcomes in place by the end of $2017-2018 .{ }^{64}$ Finally, schools must have an assessment plan in place that is being

55. Id.

56. Id. Standard 315.

57. ABA Section of Legal Educ. and Admissions to the Bar, Managing Director's Guidance Memo: Standards 301, 302, 314 AND 315 (2015), https://www.americanbar.org/content/dam/ aba/administrative/legal_education_and_admissions_to_the_bar/ governancedocuments/2015_learning outcomes_guidance.authcheckdam. pdf [https://perma.cc/7ZYY-LEWK].

58. Id. at 3 .

59. Id.

60. Id.

61. Id. at 6 .

62. ABA Section of Legal Educ. And Admissions to the Bar, Transition to and Implementation of the New Standards and Rules of Procedure for Approval of LAW Schools (2014), https://www.americanbar.org/content/dam/aba/administrative/legal education_and_admissions_to_the_bar/governancedocuments/2014 august_transition_and_implementation_of_new_aba_standards_and _rules.authcheckdam.pdf [https://perma.cc/E78A-ZKZ8].

63. Id. at 6 .

64. Id. 
implemented by the end of 2018-2019. ${ }^{65}$ Although not bound by the new standards during their site visits, schools being evaluated in 20152016 were required to report on how they were working to come into compliance. ${ }^{66}$

Around the time that the new standards were being launched, several conferences were held about assessment, and many schools sent representatives. ${ }^{67}$ As one law professor noted, "[l]ike it or not, the move to outcomes-based assessment in ABA-accredited law schools has begun." 68

\section{The NeEd for a Culture Shift Around Assessment in Higher EducAtion}

As discussed in the Introduction, law schools can learn from those who have traveled before us in assessment. Indeed, the path has not always been smooth, and other units in higher education continue to struggle with building a faculty-led culture of assessment.

Assessment has been around for decades in other disciplines. Linda Suskie asked, "Why, then, is there still foot-dragging on assessment at many colleges?" 69 The answer, she argued, varies because the "cultures, histories, values, and personalities" of institutions are so different..70 They may include a feeling of being overworked, valuing research over teaching, discord and disrespect between faculty and administrators, concern about assessment evidence being used for punishment, worry that evidence may show that a college is not as special as it thinks, and university-wide structures that establish learning outcomes without input from faculty. ${ }^{71}$ Banta and Palomba argued that, although most

65. Id.

66. Id.

67. Larry Cunningham, Conferences, Law School Assessment: Practical Resources And Insight About Assessing Student Learning OUTCOMES IN LEGAL EDUCATION, https://awschoolassessment.org/ conferences (last visited Oct. 5, 2018). Interestingly, I noted at the time that there were significant gender and status disparities in those who were tasked with implementing assessment at their schools. The attendees were overwhelming female and drawn from legal writing and clinical contract ranks.

68. Abigail Loftus DeBlasis, Building Legal Competencies: The Montessori Method as a Unifying Approach to Outcomes-Based Assessment in Law Schools, 42 Ohio N.U. L. REv. 1, 21 (2015).

69. Suskie, supra note 24, at 176.

70. Id.

71. Id. 
faculty recognize that assessment activities are a "condition of doing business," there is still resistance. ${ }^{72}$

History here is important. Initially, assessment was driven by accreditation, and the associated activities were performed by administrators, typically department chairs, associate deans, and deans. ${ }^{73}$ The data that was collected was secondary to the learning experience. For example, administrators would send surveys to students and their employers. ${ }^{74}$ As institutions became more sophisticated at assessment, plans were developed, but again by administrators, not faculty. Further, as those plans were implemented, implementation teams usually involved only small numbers of faculty. Now, accreditors are looking to see whether outcomes assessment is driving reforms in curriculum and teaching. ${ }^{75}$

Reasons for faculty resistance include the failure to internalize assessment's benefits apart from satisfying external audiences, such as accreditors; resentment about the cost of assessment; questions about the quality of data and its analysis; fear about wasting time or, conversely, information being used inappropriately; concern about teaching being a private activity; and worry that assessment intrudes upon academic freedom. ${ }^{76}$ MacDonald $^{77}$ and Haviland ${ }^{78}$ focused, in particular, on the role of external pressures, such as accreditation or administration, in causing faculty to resist assessment. As Hutchings noted: "[A]ssessment, from its earliest days, became identified with a group of actors outside academe whose patronage cast a pall over its possibilities within the academy. From the faculty point of view, this looked a lot like someone else's agenda - and not an altogether friendly someone else, at that."79

This view was echoed by Walvoord, who argued that public statements by leaders about assessment should focus on the end goal of student learning and that they should, in turn, put resources behind

72. Banta \& Palomba, supra note 1 , at 54.

73. Lane et al., supra note 19, at 2.

74. Id.

75. Id.

76. Andrade, supra note 17, at 218; Haviland et al., supra note 13, at 263.

77. Sarah K. MacDonald et al., Faculty Attitudes toward General Education Assessment: A Qualitative Study about Their Motivation, 9 RES. \& PRAC. Assessment 74, 75 (2014).

78. Haviland et al., supra note 13, at 263.

79. Pat Hutchings, Opening Doors to Faculty Involvement in Assessment, Nat'l Inst. for Learning Outcomes Assessment, Apr. 2010, at 8. 
assessment. ${ }^{80}$ Finally, the most important processes in the universityprogram review, budget requests, and general education review or reform - must have assessment of student learning as the foundation. ${ }^{81}$

Faculty are key to making assessment work. ${ }^{82}$ Since faculty are on the front lines of student learning, they should be involved in the design, study, and analysis of assessment, particularly since any reforms brought about from closing the loop on assessment will require their buy-in. ${ }^{83}$ Faculty involvement has thus been called a "gold standard" and the "key" to assessment. ${ }^{84}$ Conversely, lack of faculty support is a significant impediment to conducting meaningful assessment, ${ }^{85}$ as confirmed by a survey of provosts. ${ }^{86}$ While it is true that other factors, such as leadership, resources, and external pressure, are also important, faculty involvement remains the most important factor, since faculty members will be the ones to actually implement assessment. ${ }^{87}$

Impediments to faculty involvement with assessment include resources, rewards, communication, leadership, external influences, and institutional context. $^{88}$ In addition, collaboration-an important prerequisite to assessment activities - often does not come naturally to faculty members, whose teaching and scholarship is individual and autonomous. ${ }^{89}$ Moreover, the language of assessment can be "less than welcoming. ${ }^{900}$

80. Barbara E. Walvoord, Assessment Clear and Simple: A Practical Guide for Institutions, Departments, and General EDUCATION 27 (2d ed. 2010).

81. Id. at 28 .

82. Andrade, supra note 17, at 218; Ebersole, supra note 15, at 1; Hutchings, supra note 79 , at 6 ; KUH \& IKENBERRY, supra note 20, at 24; Wang \& Hurley, supra note 16 , at 1.

83. Wang \& Hurley, supra note 16, at 1.

84. Hutchings, supra note 79 , at 3.

85. Wang \& Hurley, supra note 16 , at 1.

86. KuH \& IKENBerRy, supra note 20 , at 24.

87. Wang \& Hurley, supra note 16 , at 3.

88. Heidi Grunwald \& Marvin W. Peterson, Factors That Promote Faculty Involvement in and Satisfaction with Institutional and Classroom Student Assessment, 44 Res. Higher Educ. 173 (2003); Haviland et al., supra note 13, at 263; Hutchings, supra note 79, at 8-9.

89. Haviland et al., supra note 13 , at 263.

90. Hutchings, supra note 79 , at 8 . 


\section{Conceptual Views of Building a Culture of Assessment}

There are several researchers who have studied and written extensively about the culture of assessment in their seminal works on programmatic assessment. Those works are largely conceptual and not empirically tested; however, they still provide valuable lessons about involving stakeholders in assessment. ${ }^{91}$

An early work in this area was Banta and Palomba's book, first published in 1999, with a second edition in 2015. ${ }^{92}$ They identified three "r's" for building a culture of assessment: responsibility, resources, and rewards. ${ }^{93}$ First, they argue that assessment must be faculty-driven. Faculty, not administrators, must have primary responsibility for the entire assessment process, from stating the purposes of assessment through acting on findings from assessment activities. To begin, faculty should be matched with tasks that are of interest to them and for which they are qualified. For example, faculty who enjoy working with data can help with data analysis. ${ }^{94}$ The key is to involve all faculty, not just a small committee - a view echoed by Banta in her 1997 article,${ }^{95}$ who called for participation across an educational community. Second, roles and responsibilities must be clearly stated and defined. Resources must be provided, including written materials and travel funds to assessment conferences. ${ }^{96}$ Gatherings on campus can provide faculty with opportunities to learn about assessment from each other. ${ }^{97}$ They should be regularly scheduled and not driven by external deadlines, such as those related to accreditation. Institutional support can contribute to faculty motivation to participate in assessment. ${ }^{98}$ In addition, recognition for good work in assessment is an important tool, as is explicit rewards, such as release time. Assessment work should be integral to promotion and tenure processes, ${ }^{99}$ but the results should not be utilized to penalize individual faculty members. Celebrating assessment successes at an institutional level can motivate others to get

91. Grunwald \& Peterson, supra note 88, at 175; Wang \& Hurley, supra note 16 , at 3 .

92. BAnta \& PALOMBA, supra note 1.

93. Id. at 41 .

94. Id.

95. Trudy W. Banta, Moving Assessment Forward: Enabling Conditions and Stumbling Blocks, 100 New Directions for Higher Educ. 79, 85 (1997).

96. Banta \& PALOMBA, supra note 1 , at $42,48$.

97. Id. at 44 .

98. Id. at 45 .

99. Id. at 46 . 
involved with assessment. Institutions can make grants available to groups of faculty to engage in particular assessment projects. ${ }^{100}$ Moreover, assessment teams should utilize locally developed assessment instruments rather than national surveys or tests. This will promote buy-in, since the local instruments will be more integrated with regular classroom work. ${ }^{101}$ Finally, assessment information must be used in "appropriate ways." 102 Thus, assessment should not be used for the purpose of faculty evaluation. ${ }^{103}$

Institutional message-sending is important. Maki stated that institutions must demonstrate an intellectual curiosity about the degree of student learning in both undergraduate and graduate programs. ${ }^{104}$ She calls this a "sustainable culture of inquiry," which is best established through an "inclusive commitment to assessment." 105 This commitment is demonstrated when (1) an institution makes a statement of commitment to assessment; (2) assessment is intentionally designed to promote "interrelated positions of inquiry" about student learning; and (3) assessment is interwoven in the roles and responsibilities of all of a university's stakeholders, including the chief executive, faculty, staff, and students. ${ }^{106}$ Adopting such a pervasive culture avoids the pitfall of assessment being temporary or marginalized. To succeed, institutions must move beyond responding to external drivers, such as accreditation, and evolve into being a "learning organization" by establishing a public commitment to assessment, organizing itself to ask questions and seek answers to questions of student learning, and creating times and places for discussion and reflection about student learning. ${ }^{107}$ Maki emphasized the importance of drawing a community together through a symbolic "principles-of-commitment statement" around assessment. ${ }^{108}$

Suskie took a slightly different starting point. ${ }^{109}$ Preferring to call the endeavor "building a culture of evidence and betterment," she argues that "improvement" is not necessarily the goal of assessment. ${ }^{110}$

100. Id. at 47 .

101. Id. at 50 .

102. Id. at 51 .

103. Id. at 53-54.

104. MAKI, supra note 23, at 3 .

105. Id. at 3,9 .

106. Id. at 9 .

107. Id. at 19 .

108. Id. at $26-27$.

109. SuskIE, supra note 24 , at 118.

110. Id. 
Instead, the focus should be on rethinking everything an institution is doing, rather than just enhancing what is already being done. This broader view of assessment guided her belief that a bottoms-up approach is needed, where faculty and staff are the driving forces behind assessment, deciding the structures, processes, and tools that they will use. Once they see the benefits of assessment, they will also see and appreciate the need for greater consistency and integration. Thus, administrators should take a back seat to the faculty, engaging themselves in a supportive rather than supervisory role. Suskie also viewed it as important to help faculty find the time for assessment by stopping or scaling back less beneficial activities and service obligations, keeping learning goals to a limited number, and providing course or service relief from taking on unusually heavy assessment activities. ${ }^{111}$ This formed the basis of her structures of value and respect for the individual engaged in assessment. Institutions value and respect faculty when they provide clear guidance, help them to learn about assessment, provide appropriate resources, help them find time to work on assessment, and help them work collaboratively in a cost-effective manner since "many hands make light work."

Suskie also made the case that individualized strategies must be developed to address the particular root causes at work for lack of faculty buy-in. ${ }^{113}$ If lack of time is an issue, other activities must be scaled back or eliminated. Likewise, lack of support can be addressed by providing guidance, coordination, and technical support. If an institution prizes research over teaching, assessment can be characterized as simply the scholarship of teaching and learning, thus fitting these activities in the research sphere, a point that Banta made as well. ${ }^{114}$ Finally, a general reluctance to change can be combatted through valuing innovation and great teaching. Overall, Suskie encouraged institutions to provide tangible solutions to cultural impediments to scholarship, such as incentives, rewards, recognitions, and honors, some of which may cost cash-strapped institutions nothing. ${ }^{115}$

Framing the purpose of assessment can contribute to buy-in. Wang and Hurley argued that faculty are more likely to be motivated to participate in assessment when they see that the purpose is improving student learning or improving the institution, rather than for reasons

111. Id. at 118-19.

112. Id. at 176 .

113. Id. at $176-78$.

114. Trudy W. Banta, Involving Faculty in Assessment, Assessment Update, Jan.-Feb. 1993, at 3-6.

115. Suskie, supra note 24 , at $178-85$. 
of accountability or accreditation. ${ }^{116}$ Thus, focusing on institutional culture is important, as is viewing assessment as a scholarly activity, a point emphasized by Suskie. ${ }^{117}$ According to Litterst and Tompkins, assessment requires all six of the qualities of scholarship: "clear goals," "adequate preparation," "appropriate methods," "significant results," "effective presentation," and "reflective critique."118

Some have argued that leadership theories can assist with promoting an assessment culture. Andrade utilized the Bolman and Deal "four frame" model to show how to change an institution's culture towards one that fosters assessment. ${ }^{119}$ Bolman and Deal argued that organizations can be examined through four "frames": structural (establishing patterns, policies, roles, and responsibilities), ${ }^{120}$ human resource (involvement, participation, training, and investment of time and money), ${ }^{121}$ political (resolving differences through negotiation), ${ }^{122}$ and symbolic (institutional culture, values, rituals, myths, stories, and ceremonies). ${ }^{123}$ Effective leaders view situations through three or, preferably, all four frames. ${ }^{124}$ Moving an institution's culture to one of assessment therefore requires focus on all four frames. The structural frame is challenged by the unique, quasi-independent nature of faculty. Still, relationships and roles can be clarified to promote assessment, such as aligning assessment efforts with broad goals of the institution, thoughtfully considering the roles of administrative offices and coordinators, designing faculty-driven processes and procedures, and agreeing on general principles of assessment. In the human resource frame, which is focused on the people in the organization, assessment should not be focused on compliance but instead on learning. Assessment should be linked to the vision of the institution. Adopting a framework of moving programs from "good-to-great" can be helpful, as is encouraging broad involvement. Trust must be built, such as by

116. Wang \& Hurley, supra note 16 , at 3.

117. Suskie, supra note 24, at 179.

118. Judith K. Litterst \& Paula Tompkins, Assessment as a Scholarship of Teaching 6-11, Paper presented at the Annual Meeting of the National Communication Association (Nov. 9-12, 2000), in U.S DeP'T OF EduC., EDuc. Res. INFo. CTR. (ERIC), ED 450427, https://files.eric.ed.gov/ fulltext/ED450427.pdf.

119. Andrade, supra note 17, at 219.

120. Lee G. Bolman \& Terrence E. Deal, Reframing Organizations: Artistry, Choice, and Leadership 52-59 (6th ed. 2017).

121. Id. at $117-33$.

122. $I d$. at 210 .

123. Id. at $242-256$.

124. Id. at 307-08. 
not using assessment results for punitive reasons. And, of course, training and other resources and rewards must be provided. The political frame requires attention to the distribution of resources, encouraging diversity of opinion among faculty, and being willing to negotiate. Finally, the symbolic frame is served through focusing on one's mission, creating a culture of learning versus assessment, communicating success, and celebrating success.

Theories of change management can also be helpful. Lane et al. sought to examine why developing a culture of assessment is difficult and why assessment is a contentious topic in most colleges and universities. ${ }^{125}$ The authors described how one business school used a change management approach to promote assessment: (1) creating a sense of urgency; (2) forming a coalition of powerful people; (3) having a vision and strategy; (4) communicating about the vision; (5) empowerment; (6) celebrating short-term wins; (7) consolidating improvements; and (8) institutionalization. The authors suggested that this method can be helpful at other institutions. ${ }^{126}$

An organizing framework for thinking about promoting assessment is the Principles of Good Practice for Assessing Student Learning from the American Association for Higher Education. Originally nine principles, the list now includes ten best practices for assessment. ${ }^{127}$ They are:

(1) The assessment of student learning begins with educational values.

(2) Assessment is most effective when it reflects an understanding of learning as multidimensional, integrated, and revealed in performance over time.

(3) Assessment works best when the programs it seeks to improve have clear, explicitly stated purposes.

(4) Assessment requires attention to outcomes but also and equally to the experiences that lead to those outcomes.

(5) Assessment works best when it is ongoing, not episodic.

(6) Assessment fosters wider improvement when representatives from across the educational community are involved.

(7) Assessment makes a difference when it begins with issues of use and illuminates questions that people really care about.

125. Lane et al., supra note 19, at 2.

126. Id. at $4-5$.

127. Banta, supra note 95 , at $80-81$. 
(8) Assessment is most likely to lead to improvement when it is part of a larger set of conditions that promote change.

(9) Through assessment, educators meet responsibilities to students and to the public.

(10) Assessment is most effective when undertaken in an environment that is receptive, supportive, and enabling. ${ }^{128}$

Principles six and seven are particularly relevant to the question of culture-building. Drawing from examples in the field, Banta argued that widespread faculty involvement in assessment is important, as is including student affairs professionals. ${ }^{129}$ And the questions they have studied have been those that are important to campus decision-making. The environment-principal ten-that is most likely to promote this type of culture is one where there is leadership around assessment, "resources for [its] implementation, an atmosphere of trust, and avenues for communicating results." 130 On the other hand, barriers to success include lack of faculty support, change in leadership (which can make it difficult to sustain assessment), change in institutional circumstances (such as budget cuts), limitations of the assessment tools and methods themselves, insufficient involvement of students, and insufficient use of results. ${ }^{131}$

Hutchings traced the history of assessment and the reasons for faculty resistance to assessment. ${ }^{132}$ Based on that history, she offered six recommendations: (1) build assessment around the regular and ongoing work of teaching and learning, putting assessment closer to the regular classroom activities that are going on anyway; (2) include assessment in faculty development; (3) include training in assessment as part of the preparation of graduate students, who will become the next generation of faculty; (4) reframe assessment as scholarship; (5) create public occasions for conversations around assessment; and (6) involve students in assessment. ${ }^{133}$ Kramer argued that the key to getting faculty buy-in for assessment is to help faculty understand that

128. Id. at 81 .

129. Id. at 85 .

130. Id. at 87 .

131. Id. at 88-90.

132. Hutchings, supra note 79 at 8-10.

133. Id. at $13-16$. 
assessment has intrinsic value through "small doses of assessment conversation." 134

The literature includes several case studies exploring how various initiatives have helped build a culture of assessment. Weiner and McMillan described a structure for promoting assessment at their institution - the use of an "assessment group" of designated faculty experts in assessment. ${ }^{135}$ The specialists receive .25 course relief or a stipend. ${ }^{136}$ Their function is to advise and support deans and other faculty members with assessment activities in their respective academic units. ${ }^{137}$ The specialists meet, as a group, every other week. Their role is supportive; they do not have jurisdiction over finances or policymaking. ${ }^{138}$ The authors credit this group with promoting a culture of assessment, as found by their regional accreditor. ${ }^{139}$ Schlitz et al. described a process at their school that resulted in the formation of a faculty learning community around the topic of assessment. ${ }^{140}$ The group worked together to develop web-based tools for assessment. The authors document an increase in the number of reports generated by the group, which in turn has led to a large data set for programmatic assessment. ${ }^{141}$ Kania-Gosche and Wilson provided examples of professional development activities that have helped their faculty to learn more about assessment. ${ }^{142}$

\section{Quantitative And Qualitative Studies on Assessment Culture}

An emerging movement is focusing on the "scholarship of assessment"- - using experimental, research-driven approaches to study

134. Philip I. Kramer, The Art of Making Assessment Anti-Venom: Injecting Assessment in Small Doses to Create a Faculty Culture of Assessment, Assessment Update, Nov.-Dec. 2009, at 8.

135. Charles S. Weiner \& Douglas N. McMillan, Transforming the Assessment Culture through the Use of Assessment Specialists at a Regional University, Assessment Update, Nov.-Dec. 2005, at 7.

136. Id. at 6 .

137. Id. at 7 .

138. Id.

139. Id. at 6 .

140. See generally Stephanie A. Schlitz et al., Developing a Culture of Assessment through a Faculty Learning Community: A Case Study, 21 Int'L J. Teaching \& Learning Higher Educ. 133 (2009).

141. Id.

142. Beth Kania-Gosche \& David W. Wilson, Building a Culture of Continuous Improvement Through Professional Development, Assessment Update, Nov.-Dec. 2017, at 5, 12. 
and promote efficient and impactful assessment practices. ${ }^{143}$ By understanding the factors likely to promote faculty satisfaction with assessment, institutions of higher learning can create data-driven processes and solutions to address them. ${ }^{144}$

Wang and Hurley conducted a survey of faculty at a liberal arts college in the Midwest, which measured faculty attitudes around assessment. ${ }^{145}$ The researchers sought to identify the variables that would predict faculty's willingness to engage in assessment. ${ }^{146}$ The study found that a faculty member's view that assessment was beneficial to teaching and learning and their perception that assessment is a scholarly activity were positively and significantly correlated with willingness to engage in assessment activities. ${ }^{147}$ This second factorperception of assessment as a scholarly activity-was the most significant. ${ }^{148}$ The remaining factors - time constraints and institutional culture - were not related to faculty willingness around assessment. ${ }^{149}$ A takeaway from this study is that faculty will be willing to put in the time necessary for assessment if they see a tangible benefit to student learning or that it is, in and of itself, a scholarly activity. ${ }^{150}$ Thus, the messaging around assessment is important, as is including assessment work in the evaluation of "scholarship" not just "teaching."

Wang and Hurley's study largely confirmed the findings from an earlier one by Grunwald and Peterson. ${ }^{152}$ That study involved surveying a random sampling of faculty at seven institutions. Those institutions were of varying types, but all used multiple approaches to assessment, used a variety of activities to support assessment, and actively used the data for decision-making within the institution. ${ }^{153}$ The survey sought to identify the factors likely to predict faculty satisfaction with an institution's approach to assessment, satisfaction with the school's support for assessment, faculty involvement with programmatic assessment, and involvement with classroom assessment. ${ }^{154}$ The third

143. Wang \& Hurley, supra note 16 , at 4.

144. McCullough \& Jones, supra note 17 , at 87-88.

145. Wang \& Hurley, supra note 16, at 2.

146. Id.

147. Id. at $8-9$.

148. Id. at 9 .

149. Id.

150. Id. at $9-10$.

151. Id. at $10-11$.

152. See generally Grunwald \& Peterson, supra note 88.

153. Id. at 181-82.

154. Id. at 173 . 
model - faculty involvement with assessment efforts at the institution level - is the concern of this literature review. ${ }^{155}$ Here, the researchers found three significant variables: (1) external influences (the greater the extent to which faculty perceive accreditation and other external efforts to be important, the more likely a professor is to be involved with assessment); (2) professional development opportunities; and (3) perception of the benefits of assessment (faculty perception of the benefits of assessment was the only variable that was a significant predictor in more than one of the four models). ${ }^{156}$ Thus, they recommend administrators involve faculty in accreditation and professional associations around assessment, provide training opportunities, and communicate the benefits of assessment to faculty. ${ }^{157}$

In their study, Haviland, Shin, and Turley applied a conceptual framework around adoption of innovation. ${ }^{158}$ Before someone can decide whether to adopt a new innovation, he or she must first understand the principles behind it. ${ }^{159}$ In assessment, faculty members must learn how to draw learning outcomes and the process and organization for conducting assessment. In addition, potential users ask whether an innovative change will be possible and worthwhile. ${ }^{160}$ Innovation is a social process; in the higher education setting, faculty adopt or reject innovations based on word of mouth. Professional development activities are a way to ensure that a population has the skills and knowledge to implement the process. ${ }^{161}$ Regular versus unsystematic experiences are more likely to result influence practice. The authors of this study conducted surveys and interviews of participants in an assessment workshop series at a college. ${ }^{162}$ The results revealed that participants in this regular, faculty-led workshop series had greater understanding of, and positive attitudes about, assessment. The workshops also influenced confidence and demonstrated that interaction among participants was important. ${ }^{163}$

Several qualitative studies have also been performed to examine how to promote faculty engagement with assessment activities. McCullough and Jones interviewed forty faculty and three assessment professionals at institutions that respected leaders in assessment had

155. Id. at 174 .

156. Id. at 200 .

157. Id.

158. Haviland et al., supra note 13, at 262.

159. Id. at 263.

160. Id.

161. Id. at $262,264$.

162. Id. at 264 .

163. Id. at 272 . 
identified as being effective at assessment. ${ }^{164}$ Several principles emerged across the multiple programs and institutions involved in the study. ${ }^{165}$ Meaningful assessment methodologies (particularly those in the form of common exams across courses or capstone projects), resources (such as financial support to attend conferences or purchase commercial exams), support (particularly from assessment offices, whose representatives were often embedded in assessment committees), faculty-centered participation, and university leadership and support were associated with faculty satisfaction. ${ }^{166}$ On the other hand, lack of comparative data across institutions, increased workload, and continuous change in assessment processes all reduced faculty satisfaction. ${ }^{167}$

MacDonald et al. conducted a qualitative study examining faculty attitudes towards assessment in general education. ${ }^{168}$ The researchers utilized expectancy-value theory, a theory of motivation that posits that engaging and persisting in a task depends on: (1) an individual's ability to do the task (expectancy); (2) his or her perception of the importance of the task (value); and (3) what a person thinks they must sacrifice to accomplish the task (cost). ${ }^{169}$ Through this lens, the authors conducted semi-structured interviews of general education coordinators. ${ }^{170}$ They found that faculty often expressed lack of expectancy or ability to engage in assessment and failed to see the usefulness or value in assessment. They also found that assessment often came with significant cost. Thus, all three factors in expectancyvalue theory were impacted. ${ }^{171}$ Nevertheless, despite the negative comments that were expressed, the respondents also expressed appreciation for the role of assessment in improving student learning. ${ }^{172}$ Thus, the authors encouraged institutions to adopt measures that would increase faculty motivation through the three factors of the theory: investing in improving faculty competency to do assessment; demonstrating the value of assessment, particularly in recognizing assessment as a scholarly activity; and working to minimize the cost of assessment. ${ }^{173}$

164. McCullough \& Jones, supra note 17, at 90.

165. Id. at 97 .

166. Id.

167. Id. at 85 .

168. MacDonald et al., supra note 77.

169. Id. at 76 .

170. Id. at $77-78$.

171. Id. at 79 .

172. Id. at $78-80$.

173. Id. at $80-82$. 
Studies have also been performed in specialized contexts. Caudle and Hammons conducted a narrative research study on assessment in community colleges. ${ }^{174}$ After conducting semi-structured interviews with nine participants at three two-year institutions, the authors concluded that faculty involvement with assessment was primarily influenced by one's perception of whether programmatic assessment is a valuable tool for improving an institution. In turn, the value an institution placed on assessment could be ascertained by (1) the allocation of resources to assessment (time and training); (2) goals of assessment that were clearly articulated; and (3) a demonstration of how assessment results are used for decision-making at the institution level. ${ }^{175} \mathrm{~A}$ qualitative study by Ebersole of community college faculty who had been active in course-level assessment found that they were able to identify a clear purpose of assessment, but that time and communication were essential for success of an assessment project. ${ }^{176}$ Sharing of best practices among colleagues was helpful. ${ }^{177}$ Faculty who had gone through the full stages of assessment had overall positive comments, while those with less experience had more mixed comments. ${ }^{178}$ Thus, the author recommended including faculty with more assessment experiences on assessment committees. ${ }^{179}$

A particular population of faculty member may have unique perspectives on assessment: contingent faculty. Danley-Scott and Scott surveyed non-tenure-track faculty at community colleges and universities in California, asking the respondents about their experiences with assessment. ${ }^{180}$ Only $13.4 \%$ of the respondents were paid for outcomes assessment activities, which the authors argued may inhibit participation in assessment. ${ }^{181}$ Responses also suggested that institutions were not stressing the reasons for collecting assessment data, providing only vague concepts of why data was being collected. ${ }^{182}$

174. LeAnn Caudle \& James O. Hammons, Strategies for Increasing Faculty Involvement in Institutional or Program Assessment, 42 CMTY. Coll. J. Res. \& PraC. 49 (2018).

175. Id. at 49 .

176. Ebersole, supra note 15, at 1, 13.

177. Id. at 13 .

178. Id. at 14 .

179. Id.

180. Jennifer Danley-Scott \& Gray Scott, The Other Half: Non-Tenure Track Faculty Thoughts on Student Learning Outcomes Assessment, 9 RES. \& Prac. Assessment 31 (2014) (defining contingent faculty as nontenured-line faculty).

181. Id. at 35 .

182. Id. at 37 . 
Fifty-seven percent of respondents reported being asked by their departments to engage in assessment, but 30.8\% reported that their department administered an assessment in their section without the faculty member's involvement. ${ }^{183}$ The authors called for greater involvement of contingent faculty in the design, discussion, and administration of assessments. ${ }^{184}$ While $60.9 \%$ said that a paid stipend would increase participation in assessment, $42.2 \%$ said they would assess more if there was a relationship with their department or they thought participating would help them learn something about their teaching effectiveness. ${ }^{185}$ Concerns expressed included whether data was useful, controls in assessment, and whether punitive actions would be taken based on the results. ${ }^{186}$ Concluding, the authors stated:

Our findings suggest departments that want to have increased NTT [non-tenure-track faculty] involvement in distributing, collecting, and rating assessments need to increase opportunities for involvement in assessment design, and they need to open communication between the institution and the NTT faculty. To further reduce anxiety over assessment, departments should close the loop with their assessment data and show the pedagogical uses for data. When departments use assessment data the way it was meant to be used, trust in the department's practice of assessment should increase. Increased participation in assessment should, in turn, lead to more awareness of what practices improve student mastery of student learning outcomes. ${ }^{187}$

A further study by Danley-Scott and Scott examined non-tenuretrack faculty's perceptions about assessment. ${ }^{188}$ This is particularly relevant because adjuncts teach the bulk of general education courses and general education is a frequent area of assessment. ${ }^{189}$ The authors analyzed responses to a survey of non-tenure-track faculty and found: (1) non-tenure-track faculty at universities were more likely than respondents from community colleges to be included in assessment activities; (2) university faculty were more likely to be provided assistance with developing course-level assessments; (3) both groups of

183. Id.

184. Id. at 40 .

185. Id. at 37 .

186. Id.

187. Id. at 40 .

188. See Gray Scott \& Jennifer Danley-Scott, Two Loops that Need Closing: Contingent Faculty Perceptions of Outcomes Assessment, 64 J. GeN. EDuC. 30 (2015).

189. Id. at 30,32 . 
respondents participated in training and professional development activities; and (4) community college faculty were more likely to be compensated for time spent with assessments. ${ }^{190}$ With respect to perceptions of assessment, community college faculty were better informed about assessment; however, university faculty were more likely to be aware of the reasons for assessment, and community college faculty received fragmented messages about assessment and how it works. ${ }^{191}$ Incentives likely to increase participation included compensation, ease of administration, and whether they believed assessment would help them learn more about their teaching effectiveness. Finally, making adjunct faculty feel as valued members of a department had a positive effect on their willingness to be involved with assessment. ${ }^{192}$ The authors recommended that non-tenure-track faculty receive the results of assessments so they can close the loop and receive training while in graduate school; employers should also offer paid training for faculty in assessment, treat contingent faculty as full members of the department, build relationships among tenure-track and contingent faculty, and shift contingent faculty to full-time status, where possible. ${ }^{193}$

Zubrow reported a case study involving adjuncts in program assessment that used a variety of tools to increase engagement: strong administrative and faculty leadership, course-embedded assessments (rather than external measures), scoring teams, and grant-funded resources. ${ }^{194}$ One consistent theme was that "systematic reflection on teaching and learning" was the most meaningful, motivating reason for adjuncts to engage in assessment. ${ }^{195}$

Student affairs is another subset of higher education that has been studied. Banta and Kuh argued that because of the complexity of the undergraduate experience, the domains of academic and student affairs should collaborate on assessment, since faculty and student affairs professionals have the most contact with students, ${ }^{196}$ a view shared by Walvoord. ${ }^{197}$ Faculty are attuned to knowledge acquisition and

190. Id. at $36-38$.

191. Id. at $38-40$.

192. Id. at $40-42$.

193. Id. at 44 .

194. Judy Zubrow, Case Study: Engaging Adjunct Faculty in Program Assessment, 2 J. Assessment \& Institutional EfFectiveness 77 (2012).

195. Id. at 77 .

196. Trudy W. Banta \& George D. Kuh, A Missing Link in Assessment: Collaboration Between Academic and Student Affairs Professionals, 30 Change: Mag. Higher Learning 40, 42 (1998).

197. WALVOORD, supra note 80 , at 31 . 
intellectual development, while student affairs professionals help students develop life skills, such as time management and cognitive processes (like moral reasoning). They offer examples of ways that academic and student affairs can collaborate, such as assessing the firstyear experience. To be successful, collaborative efforts require strong administrative commitment, joint planning, promotion of campus-wide goals related to student development, coordination of in- and out-ofclass learning activities, the design of appropriate measures, and using findings to improve the student experience.

Fuller and Lane reported on the results of data gathered from the Student Affairs Survey of Assessment Culture. ${ }^{198}$ The authors utilized exploratory factors analysis methods to determine if the survey "accurately measured hypothesized cultures of assessment." 199 There were 771 participants in the survey. The final model of the analysis showed four factors that explained $56 \%$ of the variance: (1) clear commitment to assessment, (2) assessment communication, (3) connection to change, and (4) fear of assessment may impede the goals of assessment. ${ }^{200}$ The authors then offer implications from their research; for example, clear commitment to assessment means that leaders should communicate to student affairs staff about assessment regularly and clearly. They should also share success stories regularly. ${ }^{201}$

\section{IMPLICATIONS FOR LEGAL EDUCATION}

As an initial matter and stated with some irony, there are few studies that employ rigorous quantitative or qualitative methods to measure the efficacy of particular ways at developing a culture of assessment. There is room for additional scholarship about assessment along the lines of the studies documented in Part IV of this paper. Moving forward, those interested in assessment should model the processes that they expect faculty to employ in programmatic assessment. That said, many of the findings of the empirical studies confirm what the conceptual works in Part III documented.

From these myriad studies and other works, the following major themes can be synthesized about how to build a faculty culture of assessment.

First, the purpose of assessment, which is a form of scholarship, is improving student learning, not just for satisfying accreditors. It is not for punishing faculty members whose students are not meeting the

198. Matther B. Fuller \& Forrest C. Lane, An Empirical Model of Culture of Assessment in Student Affairs, 12 Res. \& Prac. Assessment 18 (2017).

199. Id. at 19 .

200. Id. at 21-22.

201. Id. at 24 . 
outcomes. In this sense, reframing assessment is necessary. Assessment is a natural outgrowth of faculty's commitment to teaching and scholarly inquiry. ${ }^{202}$

Written assessment plans should make clear that only aggregated data will be utilized and results will never be used to punish individual faculty members in promotion, tenure, or other personnel decisions.

Second, assessment must be faculty-driven, with assessment professionals taking a supportive role. All faculty, not just a subset, must be engaged. A bottoms-up approach to assessment is best for involving the whole institution. To be successful, faculty at all levels, including adjuncts, must be engaged. The role of the non-faculty assessment professional is to support, not supervise, the faculty in their efforts. ${ }^{203}$

Law school deans should appoint committees that broadly represent the faculty and should include representation from all streams: tenuretrack, legal writing, clinical, and any others that exist at a school, such as academic support and law library faculty. If a faculty member or administrator is appointed to be a coordinator or associate dean of assessment, he or she should play an advisory or helping role in promoting assessment. Decisions about what to assess, how to assess, and what to do with the results should rest exclusively with the faculty.

Third, messaging and communication around assessment is critical, from the reasons for assessment through celebrating successes. This includes what not to communicate, such as not stating that faculty will be punished if their students do not meet outcomes. Messaging starts with the chief executive and chief academic officer but continues through to those working on assessment. Positive messaging leads to faculty buy-in, while the converse is also true. ${ }^{204}$

For law schools, messaging starts with the Dean. If the Dean sends messages, overt or otherwise, that assessment is just about checking a box for the ABA, faculty participation will be lackluster. On the other hand, if the Dean explains the value of assessment processes in helping the institution and student learning improve, faculty will be more likely to buy-in. Here, it is helpful to point out to faculty that we have already been doing assessment. For example, if disappointing bar exam results led a school to utilize data to reexamine its curriculum or teaching

202. Banta, supra note 95, at 81; Grunwald \& Peterson, supra note 88; Litterst \& Tompkins, supra note 118, at 4-5; MAKI, supra note 23; SUskIE, supra note 24, at 178-79; Wang \& Hurley, supra note 16.

203. Banta, supra note 95 , at $85,88-89$; MAKI, supra note 23, at 25; McCullough \& Jones, supra note 17, at 98-99; SuskIE, supra note 24 , at $119,128$.

204. Banta, supra note 95, at 87-88; Grunwald \& Peterson, supra note 88; MAKI, supra note 23, at 4, 25; McCullough \& Jones, supra note 17, at 94; Suskie, supra note 24, at 119-20, 137; Wang \& Hurley, supra note 16. 
methods, it was conducting assessment. This new process is simply about being systematic: collecting and using data across all of our outcomes for the purpose of continuous improvement.

Forth, faculty should be provided professional development, including in their own graduate studies. Programmatic assessment is new to many faculty. To employ a new skill, a person requires training and development. Faculty-to-faculty training and mentorship is particularly effective. ${ }^{205}$

Law schools and deans can draw on a variety of resources for faculty development. There have now been several conferences about assessment, with more likely to occur in the future. There are several books about assessment in law schools and at least one blog devoted to the topic. As this Article has demonstrated, there is also extensive literature from our colleagues across other disciplines documenting their experiences with assessment. We do not need to reinvent the wheel.

A law school that is part of a larger university can draw upon resources there, too. Many universities have an associate or vice provost devoted to assessment, and there may be an assessment committee that can serve as a resource. Our school benefitted from hiring an outside consultant to advise us on assessment practices during the early stages of our process.

Finally, pre-teaching programs, such as visiting assistant professor, L.L.M., S.J.D., and fellowship programs, should provide training in course- and programmatic-level assessment for those who will be going on the teaching market.

Fifth, resources are important. Assessment takes time but providing course relief for assessment leaders can help meet their obligations. Stipends are also helpful, particularly for adjuncts for whom service is otherwise uncompensated. Institution-wide tracking of assessment efforts often benefit from a technology solution, which also costs money. ${ }^{206}$

Most law schools are facing financial pressures as a result of decreased enrollments compared to several years ago. As a result, there may not be abundant resources available for assessment. However, a law school that is part of a university can seek to latch onto resources, such as assessment tracking software, that are being utilized by the university. The same goes for training opportunities and universitywide incentives for assessment practices.

Sixth, successes should be rewarded and recognized. In any change management scenario, it is important to reward early adopters and

205. Banta, supra note 95, at 85; Grunwald \& Peterson, supra note 88 , at 200; Haviland et al., supra note 13, at 264-65; SUSKIE, supra note 24, at 128, 180.

206. McCullough \& Jones, supra note 17 , at 94-95; SUSKIE, supra note 24 , at $142,180$. 
celebrate achievements. Public messaging is free, while monetary awards will require resources. ${ }^{207}$

Deans must celebrate assessment successes and not just those around accreditation compliance. While it is nice that an ABA site team gives a school's assessment efforts positive reviews, the better celebrations are around situations where assessment data is used to improve teaching and learning through curricular reform or other loop closing steps.

Seventh, priority should be given to utilizing faculty's existing assessment devices rather than employing externally developed tests. One way to combat faculty perceptions that assessment is externally driven is to use data from locally developed and course embedded assessments rather than tests that are developed from the outside. ${ }^{208}$

Recently-enacted ABA Standard 314 requires law schools to employ a variety of formative and summative assessments beyond the typical, end-of-semester final exam. As such, there should now be numerous "artifacts" throughout the curriculum from which assessment committees can draw data. These artifacts provide richer sources for assessment activities, since students created them within a course rather than through an artificial process, such as a mock "baby" bar exam. Utilizing these in-class assessments is also likely to lead to more buy-in, since faculty are already grading or reviewing them.

Eighth, the unique needs of contingent faculty should be considered, since they play an important role in general education, which is a ripe area for assessment. A one-size-fits-all approach to assessment does not work. Instead, unique needs of particular schools or faculty populations must be considered. ${ }^{209}$

Law schools generally do not rely on adjuncts to teach required, first-year courses. However, adjuncts often teach upper-level electives, particularly in specialty areas. As such, their help may be necessary if a school is assessing an area where they teach. Deans and assessment coordinators should look to train and involve adjuncts in assessment while keeping in mind the demands on their schedules.

Ninth, to accomplish change, stakeholders should draw on theories of leadership, business, motivation, and the social process of innovation. Assessment leaders can learn from organizational psychology and business to lead change with an institution. ${ }^{210}$

Deans, associate deans, and assessment coordinators should read and study this literature.

207. Suskie, supra note 24 , at 180.

208. Banta, supra note 95 , at 84 ; McCullough \& Jones, supra note 17 , at 87 88.

209. Danley-Scott \& Scott, supra note 180.

210. Andrade, supra note 18, at 220, 225; Haviland et al., supra note 13. 
Tenth, student affairs should be integrated with faculty and academic assessment activities. Student do not just attend classes. Much of their learning takes place outside of the classroom. Thus, student affairs professionals should be included in assessment efforts, particularly when an institution is seeking to measure broad themes or competencies. ${ }^{211}$

Most law schools have student services professionals embedded within them. They run orientation and other programming that can be the source of assessment data and places to close the loop, particularly as to those learning outcomes that focus on professionalism, ethics, and values. Some schools are including learning outcomes in professional development, ${ }^{212}$ an area naturally suited for cross-pollination.

\section{Conclusion}

Assessment in legal education is in its infancy. Deans and other assessment leaders should use this as an opportunity to lay necessary groundwork for the future. Shifting from a culture of compliance to student improvement requires leadership, careful messaging, resources, and integration. While building a culture of assessment is not easy, utilizing the ten themes outlined in this Article can help the efforts. Overall, these themes have something in common: purposeful attention to establishing and fortifying an assessment culture is the key to success.

211. Banta, supra note 95, at 85; Banta \& Kuh, supra note 196, at 42 ; Fuller \& Lane, supra note 198, at 18-19; WALVOORD, supra note 80, at 45.

212. Learning Outcomes Database, Univ. of St. Thomas Sch. of LAW: HALLORAN CTR., https://www.stthomas.edu/hollorancenter/resources forlegaleducators/learningoutcomesdatabase/ [https://perma.cc/LCW89AYT] (last updated Aug. 2018). 